\title{
DÜBLIN
}

Technological University Dublin

ARROW@TU Dublin

2016

\section{Hybrid Modelling for Vineyard Harvesting Operations}

\author{
Mohammed Mesabbah \\ Technological University Dublin \\ Amr Mahfouz \\ Technological University Dublin, amr.mahfouz@tudublin.ie \\ Mohamed Ragab \\ Technological University Dublin, mohamed.af.ragab@gmail.com
}

See next page for additional authors

Follow this and additional works at: https://arrow.tudublin.ie/buschmarcon

\section{Recommended Citation}

Mesabbah, M et al. (2016) Hybrid modelling for vineyard harvesting operations. Proceedings of the 2016 Winter Simulation Conference Washington DC, 11th - 14th December.

This Conference Paper is brought to you for free and open access by the School of Marketing at ARROW@TU Dublin. It has been accepted for inclusion in Conference papers by an authorized administrator of ARROW@TU Dublin. For more information, please contact arrow.admin@tudublin.ie, aisling.coyne@tudublin.ie, gerard.connolly@tudublin.ie.

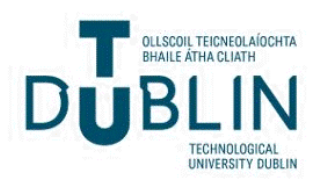


Authors

Mohammed Mesabbah, Amr Mahfouz, Mohamed Ragab, and Amr Arisha

This conference paper is available at ARROW@TU Dublin: https://arrow.tudublin.ie/buschmarcon/153 


\title{
HYBRID MODELING FOR VINEYARD HARVESTING OPERATIONS
}

\author{
Mohammed Mesabbah \\ Amr Mahfouz \\ Mohamed AF Ragab \\ Amr Arisha \\ 3S Group, College of Business \\ Dublin Institute of Technology (DIT) \\ Aungier St, Dublin 2, IRELAND
}

\begin{abstract}
Hiring workers under seasonal recruiting contracts causes significant variation of workers skills in the vineyards. This leads to inconsistent workers performance, reduction in harvesting efficiency, and increasing in grape losses rates. The objective of this research is to investigate how the variation in workers experience could impact vineyard harvesting productivity and operational cost. The complexity of the problem means that it is difficult to analyze the system parameters and their relationships using individual analytical model. Hence, a hybrid model integrating discrete event simulation (DES) and agent based modeling $(\mathrm{ABM})$ is developed and applied on a vineyard to achieve research objective. DES models harvesting operation and simulates process performance, while ABM addresses the seasonal workers heterogeneous characteristics, particularly experience variations and disparity of working days in the vineyard. The model is used to evaluate two seasonal recruiting policies against vineyard productivity, grape losses quantities, and total operational cost.
\end{abstract}

\section{INTRODUCTION}

In order to be competitive, grape growers have to show high operational performance through effective control of crop operation, accurate and timely execution of tasks, and effective use of workers. Grape harvesting is labor intensive and time consuming operation given the vulnerable, highly variable and complex work environment (Meyers et al. 2006). Many biological, technological, and sociological factors affect harvesting efficiency and cost. Among others, worker experience is a crucial factor that have direct impact on crop productivity, waste rate, and total operational cost. Agricultural workers, in particular those who are hired based on seasonal contracts, often have few qualifications and their skills are highly diverse. According to the human capital theory, introduced by Becker (2009), productivity is changed in terms of the level of experience that the individuals can accumulate. In some situations, experience is appropriate indicator of worker's productivity level, in particular when imperfect information exist (Bellit 2014). Although the direct relationship between worker's experience, skills and operations productivity, the topic has received less attention in the literature. This raises many questions between researchers and growers alike such as, how the variation in worker skills impact grape crop productivity and waste rate?, is it economical to work with low skilled, low paid workers?, and what are the alternative recruiting scenarios that improve harvesting operations performance and how much does it cost?

In order to answer these questions, systematic and analytical decision support models that analyze and simulate harvesting operation in grape vineyards are needed. Such models can be used to support decision makers and help to investigate the impact of workers experience on grape harvesting efficiency. In addition, they can be used to quantitatively evaluate labor hiring policies and investigate their effect on vineyard operations. However, only few applications of such models have been described in the 
cultivating systems and in particular at vineyards operations (Ferrer et al. 2008, Bohle, Maturana, and Vera 2010).

Using simple mathematical models to achieve this objective in a complex and dynamic cultivating system such as the vineyards is not applicable. These models tend to be static, deterministic and mostly handle one single objective. Discrete event simulation (DES), on the other hand, is an alternative approach that is able to capture the complex relationships, time dynamics and stochastic behavior of the cultivating systems (Krejci and Beamon 2012). However, this approach comes short in its ability to consider human behavior and the sociological issues in the cultivating systems - the heterogeneous characteristics of seasonal labor markets and its high turnover (Whatman and Van Beek 2008). Agent based Modelling (ABM) is effectively used in the literature to model the heterogeneous, autonomous and interacting actors within the complex systems (Higgins et al. 2010). Therefore, this paper contributes to the research area by introducing an integration between DES and ABM approaches to develop a hybrid decision support model for the vineyard. The presented model presents the complex relationships within the vineyard harvesting operations while considers the characteristics of the seasonal workers in the vineyard operations.

\section{LITERATURE REVIEW}

Grape is generally characterized by high cost of production with excessive dependency upon manual workers. It is also a highly perishable product and harvesting inefficiency could have damaging effects on product quality and storability (Ampatzidis et al., 2014). Recently, various planning and optimization algorithms have been introduced to improve the harvesting efficiency in agronomic crops (i.e. wheat, corn and cotton) (Bochtis et al., 2006, 2007). These algorithms aim to optimize the number of machines and workers for harvesting process in order to improve crop productivity, total distance travelled, fuel consumption and operational cost (Bochtis and Vougioukas, 2008; Sørensen and Bochtis, 2010). For grape crop however, few studies have been published to study the dynamics of harvesting process and its performance (Allen and Schuster 2004). Grape producers are highly dependent on the seasonal labor market to provide the required resources for the manual activities during harvesting season (Whatman and Van Beek 2008). Workers skills in harvesting have a significant impact on the cost and efficiency of grape production, however it represents a critical source of variation (Ampatzidis and Whiting 2013). Various mathematical models have been developed to address the relation between the workers skills and the performance of harvesting and crop loss rates (Arnaout and Maatouk 2010, Bohle, Maturana, and Vera 2010). However, many assumptions were applied that made the problem environment static, deterministic and deal with one single objective in most cases.

Modeling \& Simulation is used to model the dynamics of harvesting operation and examine the effect of workers skills on crop productivity. Simulation is also applied to investigate workers recruiting scenarios and their operational and economical effects. Bechar et al. (2007) used a DES model to study working practices that reduce labor involvement in harvesting in greenhouse tomato yards. Similarly, van't Ooster et al. (2014) applied DES to simulate different recruiting scenarios based on the labor skills for rose harvesting operations. However, the authors assumed homogenous characteristics for the workers and ignored their high turnover and heterogeneous characteristics. In other contexts, ABMs are developed to address workers heterogeneous characteristics in terms of the level and type of their skills. Dawid et al. (2008) introduced ABM for a macroeconomic model featuring geographical dimensions, among of them heterogeneous workers, for European policy makers to evaluate a wide range of public policies. In another study, Dal Forno and Merlone (2004) developed an optimal recruiting policy using ABM where a set of heterogeneous agents interacting dynamically within the organization. Despite that many other studies used ABM for agriculture land use (Matthews et al. 2007), there is no record of using ABM to model the crops harvesting process or evaluate the effect of workers skills on the cultivating systems.

In order to address this gap, the paper aims to integrate DES and ABM to analyze the effect of labors skills and recruiting policies on grape harvesting performance. Fakhimi and Mustafee (2012) suggested 
that combining Operations Research and Simulation techniques will reduce the limitations of individual methods and increase their capabilities. Few studies addressing this integration were reported in the fresh produce literature. For example, Dabbene, Gay, and Sacco (2008) integrated DES with analytical models to develop robust optimization models for fresh produce supply chain while preserving products quality. Hybrid simulation modeling is a growing trend in the literature, however it is still in its early development stages (Brailsford et al. 2013). Such hybrid approaches has been used in food supply chains applications (Mittal and Krejci 2013) and other domains such as healthcare (Viana et al. 2012) and transportation (Zhang, Chan, and Ukkusuri 2011).

\section{GRAPES INDUSTRY AND SEASONAL WORKERS EXPERINCE ISSUE}

\subsection{Background}

The production of table grapes for export in Egypt only began in the $20^{\text {th }}$ century coinciding with the shift toward desert farming, the employment of drip irrigation and other modern agricultural practices, and the introduction of foreign expertise to facilitate knowledge transfer then emerging industry. Today, Egypt ranks $15^{\text {th }}$ worldwide in term of grape production with a total of 1.4 million tons (FAO 2016). Ninety percent of Egyptian production is consumed locally, and close to 120 thousand tons of table grapes are exported each year predominantly to the EU, a figure which has multiplied consistently over the past 10 years (El-Sawalhy, El-Azayem, and Zaghloul 2008). However, the Egyptian table grape industry is challenged by fierce competition from other exporting countries who rival to supply the EU retailers (Diab et al. 2009). Egyptian growers and exporters hence strive to optimize their operations to ensure cost reduction and rapid entry into the market in order to remain competitive.

\subsection{Seasonal Workers Issues}

During grape harvesting seasons, seasonal workers are acquired on daily basis according to daily work volumes through a labor contractor. These labor contractors rely on seasonal workers recruited from nearby rural areas. The variations in farms needs to seasonal workers from day to day prevent the labor contractor from maintaining a consistent supply of workers for each farm. In other words, the contractor cannot guarantee that the same group of workers will be sent to the same farm every day. From the farm's managers perspective, they prefer to receive the same workers every day, regardless variation in numbers, in order to reduce training efforts and preserve experience gained by these workers.

The existence of too many growers in grapes growing regions in Egypt creates high competition on hiring trained seasonal workers. The competition causes a kind of inconsistency of seasonal workers from day to day within the same farm during the season. This inconsistency is complicated more when high turnover in such labor markets is considered, this turn over could be 3 or 2 years in some situations in Egypt due to some social factors. The failure in addressing and resolving the problem in grapes vineyards results in unstable worker productivity which will affect harvesting efficiency and operational costs in terms of wages and grape losses.

This research addresses the problem using a hybrid simulation model that integrates agent-based modeling (ABM) with discrete event simulation (DES) in order to represent the grape harvesting operations. A real case study from of a grape grower in Alexandria is used for this model. The model has two main objectives. The first objective is to introduce a decision support tool for the farm mangers to quantify seasonal workers experience and show its effect on farm's metrics, i.e., productivity and operational costs. The second objective is to examine the effect of a new recruiting policy for seasonal workers on these metrics.

\subsection{Case Study - Ragab Farms}

Ragab Farms is a third-generation producer \& exporter of premium fresh produce based in the North of Egypt. Stretching over 1700 acres of desert reclaimed land, the farm is located in Alexandria. The company has more than 300 employees and blends local competence with global expertise through the 
guidance of international technical consultants. Its main products are exported to Europe, Africa, and Asia and include table grapes, citrus, pomegranates, in addition to ornamentals. Ragab Farms manages a sizeable scale of operations, which involves the production and management of around ten thousand tons of fruit.

The grapes division is one of the most important business units in Ragab Farms. It operates on 300 acres of land and produces 10 varieties of green, red, and black grapes during the Egyptian season which extends from Mid-May until the end of August. The production area is divide into four sectors of approximately 75 acres, each controlled by a Sector Manager. Sectors are further divided into numbered blocks of 5 acres that are regarded as individual production units and are evaluated individually based on yield, quality, and financial performance. Ragab Farms produces 1500 tons of grapes per year, the majority of which are exported through the company's export subsidiary

The model in this paper represents the harvest operations for one of the products varieties that Ragab Farms grows. The vineyard comprises approximately of 39.5 acres, each acre has 700 tree and each tree produces on average 25 grape bunches of $0.5 \mathrm{~kg}$ average weight. Figure 1 shows daily harvested quantities (in tons) from this vineyard in 2015. The harvest operations for this variety lasted for 28 days with a total yield equaling 343 tons in this year.

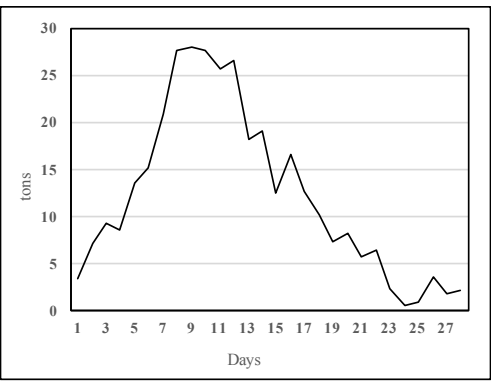

Figure 1. Daily Harvested Quantity from the vineyard for the selected variety in 2015.

\section{HYBRID MODEL DEVELOPMENT}

The developed hybrid model allows to evaluate the impact of seasonal workers recruiting policy on vineyard operational metrics that are related to productivity, hiring costs, and grapes losses costs. The model consists of five building blocks as shown in Figure 2. The "Daily Expected Harvest" block is responsible for generating daily estimate for the expected harvest volumes. The "Seasonal Workers Recruiting" block determines the number of workers needed to handle these volumes based on van 't Ooster et al. (2015) learning curve, which models the relation between workers experience and harvest productivity in cultivation systems. The workers then start the harvesting operations - "Start Harvest Operations" - which ends by calculating the experience level of the individual worker - "Update Worker Metrics" - and the vineyard operational metrics - "Update Vineyard Metrics". Afterwards, the model triggers the next harvest till the end of the unharvest grapes on the trees. The following paragraphs present the mathematical and logical models of the model activities and parameters.

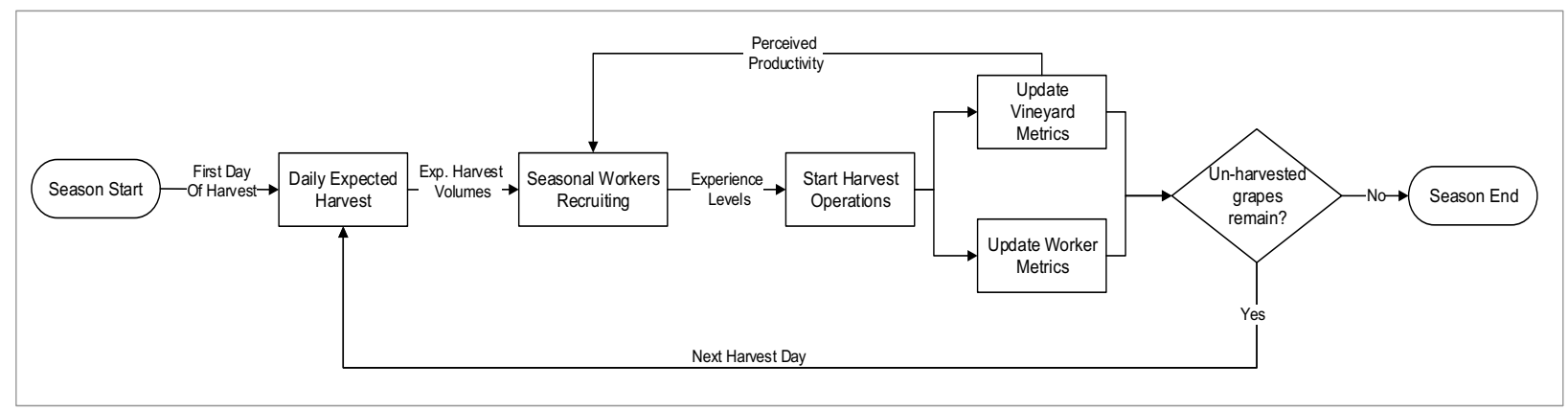

Figure 2. Model Building Blocks. 
Daily Expected Harvest Block; Grapes ripening is modeled as a discrete event that takes place every day in the vineyard. Accordingly this block is used to calculate the daily expected harvest quantity $(\widehat{\boldsymbol{Q}})$ based on the ripen bunches on each tree using the following equation:

$$
\hat{Q}(t)=w \cdot \sum_{i}^{n} F(t) \cdot B_{i}(t)
$$

Where, $\boldsymbol{t}$ is simulation time (days), $\boldsymbol{w}$ is average bunch weight, $\boldsymbol{n}$ is number of trees in the vineyard, $\boldsymbol{B}$ is number of un-harvested bunches on the tree, and $\boldsymbol{F}$ is daily fraction of harvest. This fraction represents the ratio between the quantity of grapes to be harvested on a particular day and the total quantity of un-harvest grapes on the trees at that day. The following exponential equation is used to calculate this fraction in the model:

$$
F(t)=r_{1} \cdot e^{r_{2} \cdot t}
$$

Where, $\boldsymbol{r}_{\mathbf{1}}$ and $\boldsymbol{r}_{\mathbf{2}}$ are two parameters that can be estimated by fitting the curve of the daily fraction of harvest data of 2015 (Figure 3).

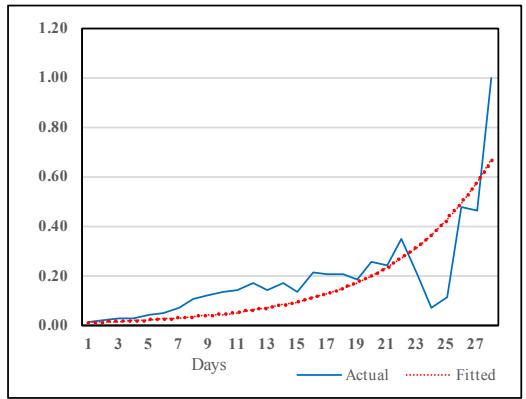

Figure 3. Daily fraction of harvest in 2015 vs. fitted daily fraction of harvest.

Seasonal Workers Recruiting Block; Recruiting workers is another discrete event that takes place every day in the vineyard once the expected quantity $(\widehat{\boldsymbol{Q}})$ of grapes that are ready for harvesting the next day is determined. Hence this block is responsible for that event by calculating the number of seasonal workers $(D)$ required to harvest the expected quantity the next day using the following equation:

$$
D(t)=\frac{\hat{Q}(t)}{P(t)}
$$

Where, $\boldsymbol{P}$ is the perceived worker productivity at day $\boldsymbol{t}$ (this will be explained later in Update Vineyard Metrics Block).

Start Harvest Operations Block; Harvesting operation is taking place once seasonal workers are recruited. Each seasonal worker is modeled as an independent agent as illustrated in the state chart at Figure 4. The state chart represents agents' (i.e. worker) different states and their relationships and dynamics in the model. When the workers are hired in the vineyard, the initial worker state is set as "Recruited". At the start of harvesting operations, the agent state is changed to be "Arrived_at_Vineyard" and then transferred into "Looking_for_Tree" state (where agent is looking for a tree with un-harvested ripen bunches). By finding such a tree the agent transfers into "Harvesting" state, which itself comprises of three sub-states that represent harvesting activities. These sub-states are 1) Checking bunches for ripeness, 2) Cutting bunches if ripened, and 3) Placing bunches in collecting boxes. The harvesting time and the loss quantities of grapes during harvesting vary according to the workers experience level. The experience level of the worker represents the level of skills that the worker gains over the working time at the vineyard. Once all grapes on the tree are harvested, the agent state is transfers either into "Finished_Work" state at the ending time of harvesting operations every day or "Looking_for_Tree" state to find another tree to harvest until all trees are harvested. When all agent states in the vineyard become at "Finished_Work", the performance metrics of the vineyard and the workers are updated. 
Mesabbah, Mahfouz, Ragab, and Arisha

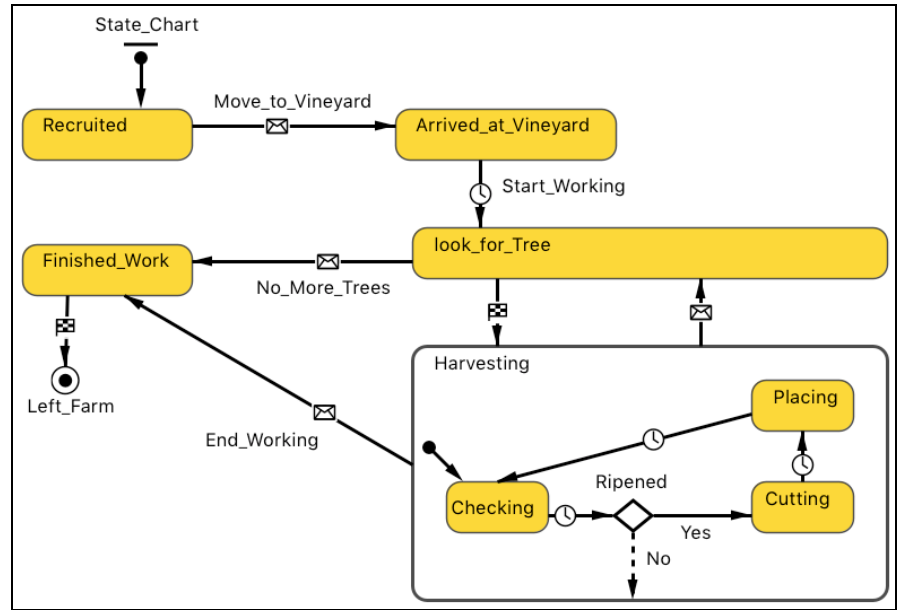

Figure 4. Seasonal Worker State Chart in the Model.

Update Worker Metrics Block; two metrics for each worker are updated at this stage: 1) number of working days $(\boldsymbol{K})$ and 2) the experience level $(\boldsymbol{E})$. The number of working days for each worker is updated as following:

$$
K_{i}(t)=\left\{\begin{array}{lc}
K_{i}(t-1)+1, & \text { if worker } i \text { is recruited at day } t \\
K_{i}(t-1), & \text { Otherwise }
\end{array} \quad \forall i=1,2, \ldots, s\right.
$$

The concept of continuous improvement and learning curves introduced by Zangwill and Kantor (1998) is used to model the update of seasonal workers experience levels using the following equation:

$$
E_{i}(t)=\min \left(E^{m}, E_{i}(0) \cdot e^{r_{3} \cdot K_{i}(t)}\right) \quad \forall i=1,2, \ldots, s
$$

Where $\boldsymbol{r}_{\mathbf{3}}$ is a learning curve parameter, $\boldsymbol{S}$ is the number of all seasonal workers, $\boldsymbol{E}(\mathbf{0})$ is the initial experience level and $\boldsymbol{E}^{\boldsymbol{m}}$ is the maximum experience level.

Update Vineyard Metrics Block; Finally this block updates the vineyard operational metrics which include: 1) actual harvested quantity $(\boldsymbol{Q}), 2)$ grapes loss quantity $(\boldsymbol{L}), 3)$ grapes loss cost $\left.\left(\boldsymbol{C}_{\boldsymbol{L}}\right), 4\right)$ hiring cost $\left(\boldsymbol{C}_{\boldsymbol{H}}\right)$, 5) perceived worker productivity $(\boldsymbol{P})$. Actual harvested quantity is simply the sum of harvested quantity by each worker. Similarly, the grapes loss quantity is the sum of grapes loss resulted by each worker. Grapes loss and hiring costs are calculated as following:

$$
\begin{aligned}
C_{L}(t) & =l_{c} \cdot L(t) \\
C_{H}(t) & =h_{c} \cdot D(t)
\end{aligned}
$$

Where $\boldsymbol{l}_{\boldsymbol{c}}$ is grapes loss cost per ton and $\boldsymbol{h}_{\boldsymbol{c}}$ is hiring cost per worker per day. perceived worker productivity is modeled using a first order delay function $\left(\right.$ Delay $\left._{\mathbf{1}}\right)$ introduced by Sterman (2000) as following:

$$
P(t)=\text { Delay }_{1}(P(0), \bar{P}(t), a)
$$

Where, $\boldsymbol{P}(\mathbf{0})$ is the initial value for the perceived worker productivity and $\boldsymbol{a}$ is time to adjust perceived worker productivity Sterman (2000), and $\overline{\boldsymbol{P}}$ is average worker productivity that can be calculated as following:

$$
\bar{P}(t)=\frac{Q(t)}{D(t)}
$$




\section{Data Collection}

The data used in this model are based on 1) historical data of harvesting season 2015 ; 2) series of interviews with farm's operational managers; and 3) Observations on harvesting operations based on site visits. Table 1 presents the model data inputs based on different sources. Table 1 presents the model parameters, their data sources and the equations that use them.

Table 1: Model Parameters.

\begin{tabular}{|l|l|l|l|}
\hline Parameter & Description & Eq. \# & Source \\
\hline $\boldsymbol{n}$ & Number of trees in the vineyard & 1 & Historical records \\
$\boldsymbol{B}(\mathbf{0})$ & Initial number of bunches on every tree & 1 & Historical records \\
$\boldsymbol{w}$ & Average bunch weight & 1 & Historical records \\
$\boldsymbol{l}_{\boldsymbol{c}}$ & Cost for grape losses per ton & 5 & Historical records \\
$\boldsymbol{h}_{\boldsymbol{c}}$ & Hiring cost per worker per day & 6 & Historical records \\
$\boldsymbol{s}$ & Number of seasonal workers in nearby rural areas & 4 & Experts Judgments \\
$\boldsymbol{P}(\mathbf{0})$ & Initial perceived worker's productivity & 7 & Experts Judgments \\
$\boldsymbol{a}$ & Time to adjust worker's productivity & 7 & Experts Judgments \\
$\boldsymbol{m}_{\mathbf{1}}$ & Mean time to check bunch ripeness & & Field observations \\
$\boldsymbol{m}_{\mathbf{2}}$ & Mean time to cut and clean ripen bunch & & Field observations \\
$\boldsymbol{m}_{\mathbf{3}}$ & Mean time to place handled bunch in box & & Field observations \\
$\boldsymbol{l}$ & Average loss fraction per bunch & Field observations \\
$\boldsymbol{r}_{\mathbf{1}}$ & First parameter of "Daily fraction of harvest" Eq. & 2 & Estimation \\
$\boldsymbol{r}_{\mathbf{2}}$ & Second parameter of "Daily fraction of harvest" Eq. & 2 & Estimation \\
$\boldsymbol{r}_{\mathbf{3}}$ & learning curve parameter & 4 & Assumption \\
$\boldsymbol{E}^{\boldsymbol{m}}$ & The maximum experience level for seasonal worker & 4 & Assumption \\
\hline
\end{tabular}

There is high turnover in seasonal workers market, which means that there exist high variations in workers' experience levels. Hence, all seasonal workers in this model are initialized with random experience levels $(\boldsymbol{E}(\mathbf{0}))$ between 1 and 5 to represent the variations in their experience levels. As mention earlier, the times to conduct harvesting activities and resultant grapes loss (as a fraction of what a worker harvests) are dependent on worker's experience level. The model assumes normal distributions for these times and the loss fraction (van 't Ooster et al. 2015). The mean values for each distribution is mapped to worker's experience level as indicated in Figure 5. Where “mean_max" and “mean_min" are the mean values for these times and loss fraction in Table 1 plus and minus (respectively) a constant value for each of them. For example, the "mean_max" time for checking bunch ripeness is $\boldsymbol{m}_{\mathbf{1}}+\boldsymbol{c}_{\mathbf{1}}$ the “mean_min" is $m_{1}-c_{1}$.

\section{OPERATIONAL IMPLICATIONS}

The ultimate objective of the model is to examine how a new recruiting policy for the seasonal workers in a grape farm will affect the vineyard performance and workers productivity. The introduced hybrid simulation model is developed using AnyLogic package. The model integrates discrete event simulation (DES) and agent based modeling (ABM) to achieve this objective. DES captures the daily harvesting process and the dynamics between vineyard entities in the operational level, while ABM models the heterogeneous characteristics of the workers recruited every day. Every worker is represented as independent agent of a unique harvesting performance based on its experience level. 
Mesabbah, Mahfouz, Ragab, and Arisha

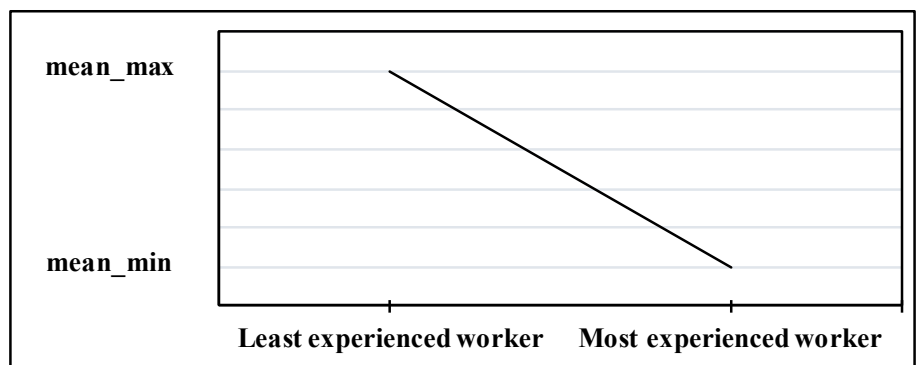

Figure 5. Map between Worker's experience and mean value for normal distributions of activities times and grapes loss fraction.

Worker contractors are asked to secure the required number of seasonal workers $(\boldsymbol{D})$ at the start of every day. The number of workers is determined based on a daily prediction of the grape quantities ready to be harvested. According to the current recruiting policy (i.e. BAU ), Although the contractor can secure the required number of workers, different workers are supplied every day. Under the proposed recruiting Policy vineyard managers are willing to incur extra hiring cost $\left(\boldsymbol{h}_{\boldsymbol{c}}\right)$ to hire experienced workers that have been recruited before in the vineyard (i.e. workers with the highest working days $(\boldsymbol{K})$ in the vineyard).

There exists high variation in worker's experience level, which results in inconsistent harvesting performance and reducing worker's productivity. However, when vineyard managers determine the needed number of workers at any particular day $(\boldsymbol{D})$, they based their decision on a collective productivity figure rather than the productivity of individual workers. Under $\boldsymbol{B} \boldsymbol{A} \boldsymbol{U}$ policy a steady-state behavior of the average workers productivity $(\overline{\boldsymbol{P}})$ is resulted, and consequently its effect on the number of recruited workers is neutralized, see Figure 6.b. On the other hand, and as it is illustrated in Figure 6.b, the average workers productivity $(\overline{\boldsymbol{P}})$ is significantly improving over the time under the new recruiting Policy due to the continuous development in workers experience, see Figure 6.a. Hence, and as main implication of the new recruiting Policy, the number of recruited workers is significantly decreased because of the improved workers experience levels and productivities, see Figure 6.c.

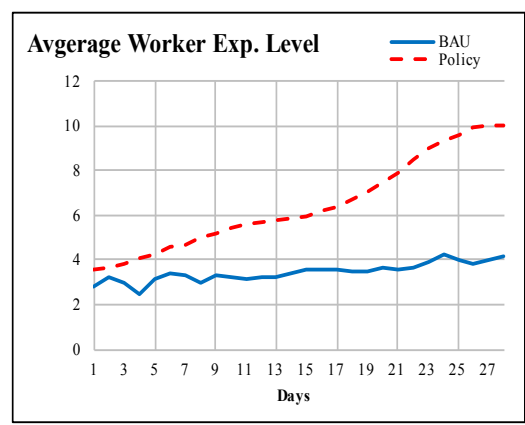

(a)

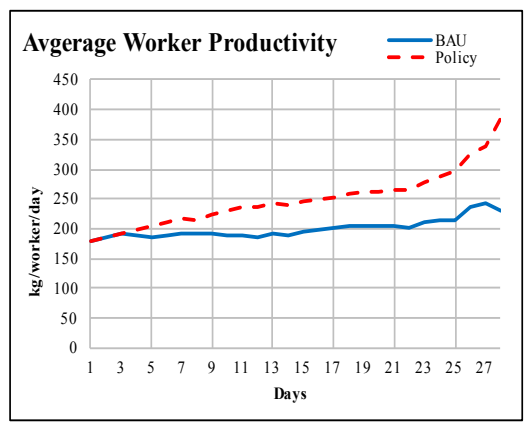

(b)

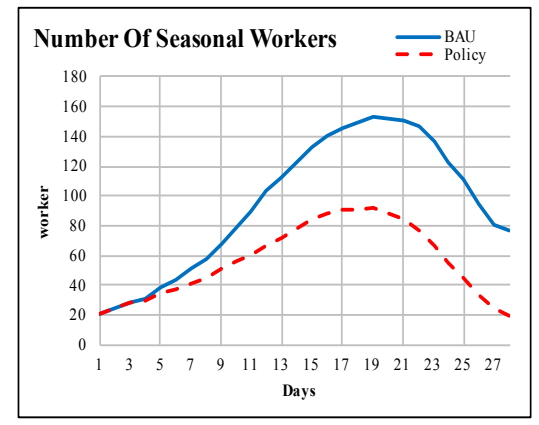

(c)

Figure 6. Average Seasonal Worker Experience level and Productivity and Number of Seasonal Workers recruited every day under the two scenarios.

More positive implications can be observed by applying the new recruiting Policy in the grape Vineyards. Figure 7.a and 7.b show the improvement in harvesting operations efficiency and the reduction in grapes loss quantities during harvest activities. Around 7 tons of grapes are saved because of improving harvest efficiency under the proposed Policy. This quantity represents about $41 \%$ of total losses of grape quantities under $\boldsymbol{B} \boldsymbol{A} \boldsymbol{U}$ policy. This improvement can be explained due to the less variation in workers performance along the harvesting season under the proposed recruiting Policy. 
Mesabbah, Mahfouz, Ragab, and Arisha

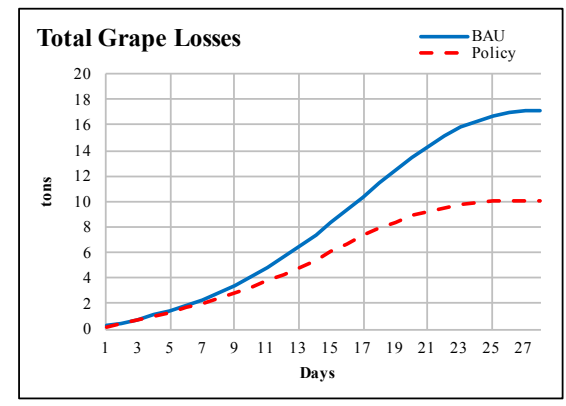

(a)

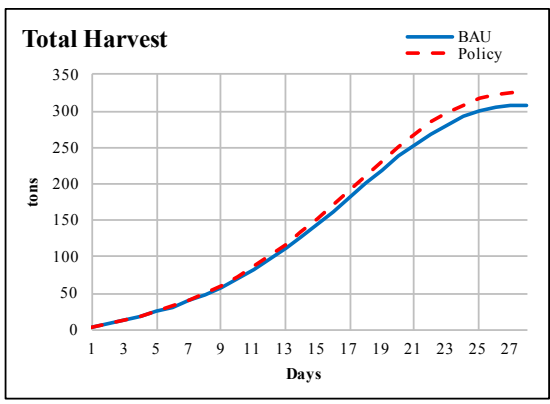

(b)

Figure 7. Accumulated grapes losses and total harvested grapes under the two scenarios.

Hence, It is obvious how the proposed recruiting Policy positively impact workers productivity, harvesting efficiency, and total losses of grape quantities. However, the question that need to be addressed here is "does the new recruiting policy is cost effective? The answer to this question is dependent on the extra hiring cost $\left(\boldsymbol{h}_{\boldsymbol{c}}\right)$ the vineyard manager is willing to afford under the proposed policy. The model is used to investigate different values for the hiring cost including $25 \%, 50 \%, 75 \%$ and $100 \%$ increasing of the original hiring cost $\left(\boldsymbol{h}_{\boldsymbol{c}}\right)$. Figure 8 present the impact of the four hiring costs on the vineyard total operational costs based on equations 5 and 6 . The results in Figures 8 (a,b,c and d) showed that the new recruiting Policy is cost effective only if the managers pay extra hiring cost less than $75 \%$ of the regular cost.

The results showed that workers experience directly influences grape harvesting efficiency and total operational cost of the grape cultivation system. This relation is illustrated through the dramatic improvement in the vineyard metrics and workers performance against the changes in the recruiting scenarios. Although new recruiting scenario resulted in better values for all vineyard metrics, it was necessary to evaluate its financial impact on the operational cost. Hybrid simulation technology is effectively used to achieve this objective given its ability in modeling multidimensional and complex systems. The results of the model has suggested that grape growers need to pay more attention to consistently develop seasonal worker experience, despite the higher hiring cost that they may incur.

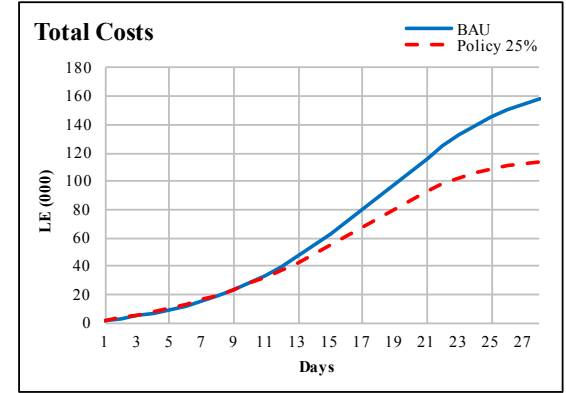

(a)

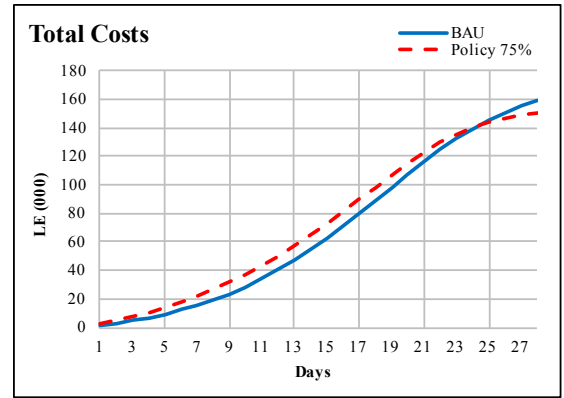

(c)

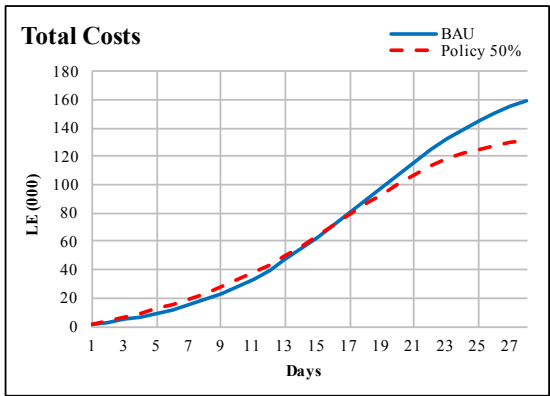

(b)

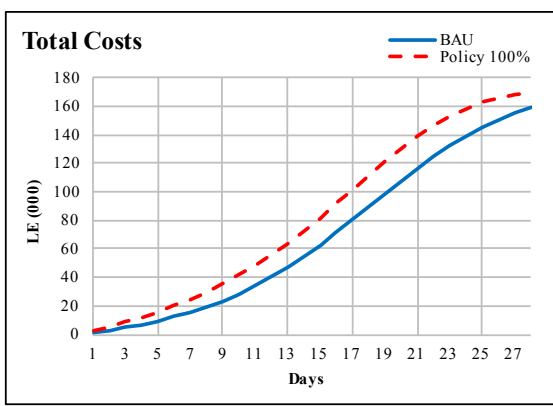

(d)

Figure 8 . Total Costs of BAU against Policy with $25 \%, 50 \%, 75 \%$ and $100 \%$ of hiring cost $\left(\boldsymbol{h}_{\boldsymbol{c}}\right)$. 


\section{CONCLUSIONS}

Grape harvesting is a labor-intensive process with a seasonality nature. The process performance is highly dependent on workers' experience and quality of training. This research attempts to address the sensitivity of the harvesting performance subject to the labor's recruitment and training. A hybrid model of DES$\mathrm{ABM}$ of vineyard harvest operations of table grape grower in Egypt is developed to simulate the dynamics in the processes. The model objective is to evaluate the current recruiting practices of the seasonal workers and emphasize their effect on vineyard's operational metrics - productivity and operational costs. It is also used to examine the efficacy of the proposed recruiting policy and investigate its effect on the performance metrics.

The application of the model was well-received by the management team and they appreciated the insights they gained from modeling grape harvesting dynamics while capturing the heterogeneous characteristics of the harvesters. The management found the model helpful in examining the impact of their operational strategies on the productivity measures. They also found that opportunities to be more productive and efficient can exist, and in some cases with less cost.

Results show that the variations in workers skills have a significant impact on grape harvesting efficiency and also suggest that it is not always economical to work with lower skilled workers to save wages. Contrary to the current policy, recruiting trained and skilled labors will have a better impact on profitability even though their wages per day are higher. Based on the model, the proposed policy is to preserve workers with experience where this is possible and also provide a systematic training scheme for new recruits whenever time permits. Despite the increase of costs related to keep workers and preserve experience, the operational costs is reduced compared to the total cost they incur under the current recruiting policy. Finally, there is a potential future research work which can include harvesting and handling processes of all grape varieties produced by Ragab Farms. Seasonal workers are still core asset for post-harvest processes such as handling and packing - this part was not modeled in the current solution.

\section{REFERENCES}

Allen, S. J., and E. W. Schuster. 2004. "Controlling the Risk For an Agricultural Harvest." Manufacturing and Service Operations Management 6 (3):225-236.

Ampatzidis, Y. G., and M. D. Whiting. 2013. "Training System Affects Sweet Cherry Harvest Efficiency." Hortscience 48 (5):547-555.

Ampatzidis, Yiannis G., Stavros G. Vougioukas, Matthew D. Whiting, and Qin Zhang. 2014. "Applying the machine repair model to improve efficiency of harvesting fruit." Biosystems Engineering 120:2533.

Arnaout, J. P. M., and M. Maatouk. 2010. "Optimization of Quality and Operational Costs Through Improved Scheduling of Harvest Operations." International Transactions in Operational Research 17 (5):595-605.

Bechar, A, S Yosef, S Netanyahu, and Y Edan. 2007. "Improvement of Work Methods in Tomato Greenhouses Using Simulation." Transactions of the ASABE 50 (2):331-338.

Becker, Gary S. 2009. Human Capital: A Theoretical and Empirical Analysis, with Special Reference to Education: University of Chicago Press.

Bellit, S. 2014. "The Career Paths of Agricultural Workers: What is The Impact of Temporary Contracts?" Agricultural Economics 60 (12):553-569.

Bochtis, D. D., and S. G. Vougioukas. 2008. "Minimising the Non-Working Distance Travelled by Machines Operating in a Headland Field Pattern." Biosystems engineering 101 (1):1-12.

Bochtis, D., S. Vougioukas, C. Tsatsarelis, and Y. Ampatzidis. 2007. "Optimal Dynamic Motion Sequence Generation for Multiple Harvesters." Agricultural Engineering International: CIGR Journal. 
Bohle, C., S. Maturana, and J. Vera. 2010. "A Robust Optimization Approach to Wine Grape Harvesting Scheduling." European Journal of Operational Research 200 (1):245-252.

Brailsford, Sally C, Joe Viana, Stuart Rossiter, Andrew Channon, and Andrew J Lotery. 2013. "Hybrid Simulation for Health and Social Care: The Way Forward, or More Trouble Than It's Worth?" In 2013 Winter Simulations Conference (WSC):edited by R. Pasupathy, S.-H. Kim, A. Tolk, R. Hill, and M. E. Kuhl, 258-269. Piscataway, New Jersey: Institute of Electrical and Electronics Engineers, Inc.

Dabbene, F., P. Gay, and N. Sacco. 2008. "Optimisation of Fresh-Food Supply Chains in Uncertain Environments, Part I: Background and Methodology." Biosystems Engineering 99 (3):348-359.

Dal Forno, Arianna, and Ugo Merlone. 2004. "Personnel Turnover in Organizations: An Agent-Based Simulation Model." Nonlinear dynamics, psychology, and life sciences 8 (2):205.

Dawid, Herbert, Simon Gemkow, Philipp Harting, Kordian Kabus, Michael Neugart, and Klaus Wersching. 2008. "Skills, Innovation, and Growth: An Agent-Based Policy Analysis." Jahrbücher für Nationalökonomie und Statistik 228 (2-3):251-275.

Diab, Yaser AA, Magdi AA Mousa, Daniel F Warnock, and David E Hahn. 2009. "Opportunities for Producing Table Grapes in Egypt for the Export Market: A Decision Case Study." International Food and Agribusiness Management Review 12 (2):57-69.

El-Sawalhy, Hamdi A, MGM Abou El-Azayem, and Ezzat A Zaghloul. 2008. "Analysis of Egyptian Grapes Market Shares in the World Markets." American-Eurasian Journal of Agricultural \& Environmental Sci 3 (4):656-662.

Fadhel, A., S. Kooli, A. Farhat, and A. Bellghith. 2005. "Study of the Solar Drying of Grapes by Three Different Processes." Desalination 185 (1):535-541.

Fakhimi, Masoud, and Navonil Mustafee. 2012. "Applications of Operations Research within the UK Healthcare Context." Proceedings of the Operational Research Society Simulation Workshop.

FAO. 2016. "FAOSTATS." Accessed 4/4/2016. http://faostat3.fao.org/browse/Q/QC/E.

Ferrer, J. C., A. Mac Cawley, S. Maturana, S. Toloza, and J. Vera. 2008. "An Optimization Approach for Scheduling Wine Grape Harvest Operations." International Journal of Production Economics 112 (2):985-999.

Higgins, A. J., C. J. Miller, A. A. Archer, T. Ton, C. S. Fletcher, and R. R. J. McAllister. 2010. "Challenges of Operations Research Practice in Agricultural Value Chains." Journal of the Operational Research Society 61 (6):964-973.

Krejci, Caroline C, and Benita M Beamon. 2012. "Modeling Food Supply Chains Using Multi-Agent Simulation." In 2012 Winter Simulations Conference (WSC):edited by C. Laroque, J. Himmelspach, R. Pasupathy, O. Rose, and A.M. Uhrmacher, 1167-1178. Piscataway, New Jersey: Institute of Electrical and Electronics Engineers, Inc.

Matthews, Robin B, Nigel G Gilbert, Alan Roach, J Gary Polhill, and Nick M Gotts. 2007. "Agent-Based Land-Use Models: A Review of Applications." Landscape Ecology 22 (10):1447-1459.

Meyers, J, J Miles, Julia Faucett, Fadi Fathallah, Ira Janowitz, Rhonda Smith, and E Weber. 2006. "Smaller Loads Reduce Risk of Back Injuries During Wine Grape Harvest." California agriculture 60 (1):25-31.

Mittal, Anuj, and Caroline C. Krejci. 2013. "A Hybrid Simulation Model of Inbound Logistics Operations in Regional Food Supply Systems." In 2015 Winter Simulations Conference (WSC):edited by L. Yilmaz, W. K. V. Chan, I. Moon, T. M. K. Roeder, C. Macal, and M. D. Rossett, 1560-1549. Piscataway, New Jersey: Institute of Electrical and Electronics Engineers, Inc.

PMA. 2015. "Top 20 Fruits and Vegetables Sold in the U.S." Accessed 1/4/2016. http://www.pma.com/content/articles/2016/03/top-20-fruits-and-vegetables-sold-in-the-us.

Sørensen, Claus G., and Dionysis D. Bochtis. 2010. "Conceptual Model of Fleet Management in Agriculture." Biosystems Engineering 105 (1):41-50.

Sterman, John D. 2000. Business Dynamics: Systems Thinking and Modeling for a Complex World. Vol. 19: Irwin/McGraw-Hill Boston. 
Stulina, Galina V. 2015. "Role of Women in the Irrigated Agriculture Sector in the Fergana Valley: Findings of Field Surveys." Irrigation and Drainage 64 (4):491-500.

van 't Ooster, A., J. Bontsema, E. J. van Henten, and S. Hemming. 2015. "Model-Based Analysis of Skill Oriented Labour Management in a Multi-Operations and Multi-Worker Static Cut Rose Cultivation System." Biosystems Engineering 135:87-102.

van't Ooster, A., J. Bontsema, E. J. van Henten, and S. Hemming. 2014. "Simulation of Harvest Operations in a Static Rose Cultivation System." Biosystems Engineering 120:34-46.

Viana, Joe, Stuart Rossiter, Andrew A Channon, Sally C Brailsford, and Andrew Lotery. 2012. "A MultiParadigm, Whole System View of Health and Social Care for Age-Related Macular Degeneration." In 2012 Winter Simulations Conference (WSC):edited by C. Laroque, J. Himmelspach, R. Pasupathy, O. Rose, and A.M. Uhrmacher, 1070-1081. Piscataway, New Jersey: Institute of Electrical and Electronics Engineers, Inc.

Whatman, Richard, and Jerf Van Beek. 2008. "The Seasonal Labour Strategy and the Role of Recognised Seasonal Employer (RSE) in Helping Make Transformative Changes for Employers and Industry." Proceedings of Labour, Employment and Work in New Zealand (LEW13), Wellington, New Zealand.

Zangwill, W. I., and P. B. Kantor. 1998. "Toward a Theory of Continuous Improvement and the Learning Curve." Management Science 44 (7):910-920.

Zhang, Bo, Wai Kin Chan, and Satish V. Ukkusuri. 2011. "Agent-Based Discrete-Event Hybrid Space Modeling Approach for Transportation Evacuation Simulation." In 2011 Winter Simulations Conference (WSC):edited by S. Jain, R.R. Creasey, J. Himmelspach, K.P. White, and M. Fu, eds., 99209. Piscataway, New Jersey: Institute of Electrical and Electronics Engineers, Inc

\section{AUTHOR BIOGRAPHIES}

MOHAMMED MESABBAH, M.Sc. is a researcher in 3S Group (A research unit specialized in simulation and optimization of complex business processes) in College of Business - Dublin Institute of Technology (DIT)). He joined the 3S Group in 2013. He has a B.Sc. degree in Operations Research and decision support from Cairo University and M.Sc. in System Dynamics from University of Bergen. His research interests include Decision Support, Modeling and Simulation, Optimization, Computational intelligence and Game Theory. mohamed.mesabbah@dit.ie.

AMR MAHFOUZ, He is a project manager at 3S Group, College of Business, DIT. Dr. Mahfouz has received his $\mathrm{PhD}$ in operations and supply chain management from DIT and he is currently a lecturer in School of Management, DIT. He has published several journal and international conference articles in the area of supply chain management, simulation and lean supply chain. His research interest includes lean supply chain, simulation modeling applications in business process analysis, and supply chain risk analysis.amr.mahfouz@dit.ie

MOHAMED AF RAGAB, PhD. is a Senior Researcher in 3S Group, College of Business, DIT, Ireland. He received his B.Sc. in Industrial Engineering and his MBA from the American University in Cairo, and his PhD from DIT in 2015 for his work on Knowledge Management. Dr. Ragab's work was published in a number of International peer-reviews journals and conferences and received a Highly Commended Paper Award for Academic Excellence from Emerald Publishing Group.mohamed.ragab@mydit.ie.

AMR ARISHA, Ph.D. is the Director of the $3 \mathrm{~S}$ Group and the Head of International Business Department at College of Business, DIT. He received his PhD in Industrial Engineering from Dublin City University (DCU). Intel-Ireland has sponsored his research from 2000 - 2005. His research path is focused on the ultimate goal of developing an integrated solution framework leveraging existing mathematical and systems tools from a number of fundamental approaches including system analysis, value stream mapping, stochastic modeling, game theory, simulation and optimization. His work places the quest for operations excellence at the heart of many contemporary challenges in applications such as healthcare, supply-chain management, production scheduling, and teaching/training. He is a member in IIE, IMECH, IEI, ESE, ORS, IEEE and ASME and Chief Examiner at MII. amr.arisha@dit.ie. 